\title{
Emotional Competence Among Day Scholars and Hostellers
}

\author{
Prerana Sinha ${ }^{1 *}$, Dr. Sunitha Damodar ${ }^{2}$, Nachiketh B. ${ }^{3}$
}

\section{ABSTRACT}

The present research aims to study the emotional competence among day scholars and hostellers. Emotional competence is the efficacy of an individual to deal with emotional situations effectively. The word competence refers to mastery over some skill which indicates that competence can develop over time. Saarni proposes that the social environment influences the process of developing emotional competence. This research is aimed at studying the effect the living status has on emotional competence. In the present study, the Emotional Competence scale by Bhardwaj and Sharma (1998) was used which consists of 30 items measuring five domains and the score ranges from 30 to 150 . A total of 123 samples was collected for this purpose. For analysis two-way ANOVA was used. The result indicated that there is no effect of living status on emotional competence, however, there was a significant effect of gender on emotional competence. There was no significant interaction effect of gender and living status on emotional competence.

\section{Keywords: Emotional competence, Day scholars, Hostellers, Living status}

$\mathrm{E}$ motional competence is defined as the efficiency of an individual to deal with emotional situations effectively. According to Sharma and Bharadwaj (2007), it consists of five competencies that are adequate depth of feeling, adequate expression, and control of emotions, ability to function with emotions, ability to cope with problem emotions, and enrichment of positive emotions. It can be understood as a person's ability to express and respond to their feelings. According to Goleman (1998), "An emotional competence is a learned capability based on emotional intelligence that results in an outstanding performance at work." Saarni (1999) defines emotional competence as the capacity for self-efficacy in emotion-eliciting social situations. It involves having an awareness of own emotions and those of others, and ability to name the emotions, empathy, sympathy, ability to differentiate internal subjectivity from outward expression, adaptive coping with aversive or distressing emotions, awareness of emotional communication within relationships, and emotional self-efficacy (Saarni,1999). Overall, emotional Competence can be understood as the ability to identify and manage one's emotions which includes knowing how to nurture your emotional state, delay gratification, and cope with failure and loss. It

\footnotetext{
${ }^{1}$ Research Scholar, Indian Institute of Psychology and Research, Bangalore, Karnataka, India

${ }^{2}$ Associate Professor, Indian Institute of Psychology and Research, Bangalore, Karnataka, India

${ }^{3}$ Assistant Professor, Indian Institute of Psychology and Research, Bangalore, Karnataka, India

*Corresponding Author
}

Received: September 28, 2021; Revision Received: December 25, 2021; Accepted: December 28, 2021

(C) 2021, Sinha P., Damodar S. \& Nachiketh B.; licensee IJIP. This is an Open Access Research distributed under the terms of the Creative Commons Attribution License (www.creativecommons.org/licenses/by/2.0), which permits unrestricted use, distribution, and reproduction in any Medium, provided the original work is properly cited. 


\section{Emotional Competence Among Day Scholars and Hostellers}

also includes recognizing ways to control impulses, optimally use good judgment and modify emotions in response to others' emotions and reactions.

The word "competence" refers to a person's mastery of some skills (Lau \& Wu, 2012). Emotional competence consists of the capacity to tactfully respond to emotional stimuli elicited by the various situation, having high self-esteem and optimism, communication, tackling emotional upsets such as conflicts, enjoying emotions, relating to others, emotional self-control, avoiding emotional exhaustion, and learning to avoid the negativity of emotions (Sharma \& Lata, 2013). Goleman (1995) describes emotional competence as a learned capability that is based on emotional intelligence. Emotional intelligence determines an individuals' potential for learning practical skills based on the five elements: self-awareness, motivation, self-regulation, empathy, and adeptness in relationships.

Emotional competence (EC) can be understood as a cluster of skills that can be applied to many types of emotion-related situations. The special ability to identify and differentiate between various emotions is crucial for the adequate development of youth. Saarni suggested that the regulation and stabilization of emotions may not be inherited or inborn; it is a skill that can be nurtured and cultivated as a person grows.

Interestingly, Lazarus and Cosmos stated that emotional competence can be developed as a result of dynamic interactions with significant others in the environment (Lau \& Wu, 2012). An individual gains an understanding of the meanings of different emotions by the environment and interaction as one moves through different developmental stages. During early years, parents support healthy social and emotional development in children when they model how to express and communicate emotions effectively, self-regulate, and make friends. Social and emotional competence plays a crucial role in developing sound relationships with parents, adults, and peers. However, Saarni discusses emotional competence under the assumption that emotional development would be affected by the interactions among human beings and with the culture and social world. Hence, emotional competence can be developed throughout life through the process of socialization. One way to acquire the skills to regulate emotions appropriately can be achieved through interpreting emotional stimuli from the environment. Another way is by placing emphasis on interpersonal and social interaction within the environment. This indicates the importance of social interaction in the development of emotional competence. Since an individuals' initial and most prominent social interaction is their family, family plays an important role development of emotional competence. Saarni's approach to theory in each of these fields suggests integrative and focus on self-development with a strong social-constructivist perspective.

The transition from school to college is a complex process for most students. Adjusting to college life brings changes in values and attitudes for most of the students. It is also a period during which students are in high for their needs for belongingness. The new circumstances can either satisfy their need or things may become worse. Living in a hostel is a different experience it takes an individual out of their comfort zone and exposes them to several different conditions. In hostels or PG, students live with each other and learn the value of discipline and cooperation. Students develop a sense of friendship and fellow feeling during their stay. Staying away from home teaches students a sense of responsibility in matters of taking care of academics, health, food, and be more self-dependent. 


\section{Emotional Competence Among Day Scholars and Hostellers}

Day scholars are students staying at home with their family during their course of education whereas hostellers are ones staying away from home in hostels with other students coming from different backgrounds. Living at home, students have love, support, and understanding of their loved ones. However, students staying away from home have to face various situations like make a curricular and extra-curricular choice, acquire basic study skills for, optimum achievements; live with and share facilities with students from varied socioeconomic, backgrounds, adjust to the peers, and so on (Wadder \& Aminabhavi, 2010).

\section{Background/ Premise of the study}

Day scholars face different conditions as compared to hostellers. Day scholars live at home where they receive love, support, and understanding from their parents and siblings helps in the development of self-efficacy and emotional intelligence (Wadder \& Aminabhavi, 2010) which in turn can affect the development of emotional competence among students since emotional intelligence forms a base for emotional competence (Vaida, 2015). Staying in a hostel, away from home and family members one learns to be independent and is faced with a different set of challenges. Staying with parents at home and staying away from home at a hostel or as a paying guest definitely impacts the personality development of a student (Wadder \& Aminabhavi, 2010).

This study proposes to assess the level of competence among students based on their living status i.e based on whether they live with their family at home or with other students in hostels or PG. This study will help to gain insight into the importance of family support in the development of emotional competence.

\section{REVIEW OF PREVIOUS STUDIES}

A study by Bhat and Khan (2018) indicated significant correlates and predictors of emotional competence were mental health, social behavior, maladjustment, forgiveness, happiness, adolescent risky behavior, well-being, emotional abilities, self-efficacy, empathy, life satisfaction, social support, resilience, psychopathology, risk behaviors, and self-esteem. Also, age, gender, type of school, working \& non-working conditions, and residential locality from a demographic perspective emerged as significant correlates and predictors.

Shazia and Kiran (2018) study revealed a non-significant difference between psychological well-being and emotional competence among children living in shelter homes and street children. The study further highlighted higher emotional competence in girls than boys, although, psychological well-being was similar between boys and girls.

The study by Sunny, Ahammed, Gopi, Tom, and Kurian (2018) indicated that there is no significant difference in the emotional intelligence among adolescent male and female day scholars and hostellers.

A comparative study by Baruah and Saha (2018) revealed that adolescent boys and girls differ significantly on emotional competence on three major competencies namely adequate expression and control of emotions (AECE), ability to function with emotions (AFE), and ability to cope with problem emotions (ACPE).

A study by Arora and Kaur (2017) indicated that there is no significant difference in the high and low groups of emotional competence \& depression in terms of gender. The study further reveals that there is a negative relationship between Emotional Competence and Depression. 


\section{Emotional Competence Among Day Scholars and Hostellers}

A comparative study by Jacob and Kaushik (2017) to assess and compare the health status and academic progress among day scholars and hostellers revealed that students staying at home have better health status because of the parental care, healthy food, and safe drinking water, whereas those students staying in the hostel have good academic progress due to less time of travel, participation in group study and help from other fellow hostel mates.

The study by Sandhya G (2017) indicated no difference in emotional competence of adolescents of working and non-working mothers. The same finding was observed in the case of male adolescents of working and non-working mothers but female adolescents of working mothers scored higher mean values than female adolescents of non-working mothers.

Emotional Competence among college students in Tiruchirappalli city by V. Jansi William (2017) indicated no significant difference in the perception of emotional competence among the students based on their domicile. But there is a significant difference found in emotional sensitivity, emotional insulation, and emotional withdrawal among students based on their gender and stream of study.

A study conducted by Ajay Kumar and Vani Thapar (2015) aimed to study the levels of emotional competence and adjustment of secondary school students revealed a significant positive relationship between emotional competence and adjustment among secondary school students belonging to nuclear families.

A study on the emotional competence and family environment of school children by Banrisha S. Basaiawmoit (2014) indicated a significant difference between Dharwad and Shillong children in the overall emotional competence where Dharwad children had better emotional competence. In the case of family environment dimensions, a significant difference was observed in cohesion, expressiveness, acceptance and caring, and organization which had an influence on overall emotional competence. The study also revealed that boys had better emotional competence than girls.

Research by Dr. Mangal Singh (2014) to assess the degree of social competence among the day scholar and hostellers indicated that there is no significant difference with respect to the degree of social competence. There is a significant difference between hosteller boys and hosteller girls with respect to the degree of social competence. There is no significant difference in social competence among day scholar boys and day scholar girls.

A comparative study of emotional competence among students in relation to their gender and type of institute by Sharma and Lata (2013) revealed that gender does not affect emotional competence.

A comparative study on the emotional competence of sports and non-sports personnel was conducted by Dr. Shyam Lata Juyal and Anu Dandona (2012). The finding indicated that sports personnel are more competent emotionally than non-sports personnel, day scholars showed more competence than the boarders and in gender, sports boys of day scholars are found to be highly competent emotionally than the girls of non-sports as well as boarders.

A study on the self-efficacy and emotional intelligence of PG Students by M.S. Waddar and V. A. Aminabhavi (2010) indicated that PG students staying at home have significantly higher self-efficacy and overall emotional intelligence compared to hostilities. 


\section{METHODOLOGY}

\section{Objectives}

- To compare the emotional competence among day scholars and hostellers.

- To compare gender differences in emotional competence.

- To study the effect of living status and gender on emotional competence.

\section{Hypothesis}

- There is no significant difference in emotional competence among day scholars and hostellers.

- There is no significant gender difference in emotional competence.

- There is no significant gender difference in emotional competence among day scholars and hostellers.

\section{Variables}

Independent variable. 1) Living status of students; day scholars and hostellers

2) Gender; male students and female students

Dependent Variable. Emotional Competence.

\section{Operational Definition}

- Emotional competence. Emotional competence is the ability to appropriately display one's emotions and inner feelings. It is considered a social skill to interpret and understand the emotions displayed by others as well as one's own.

- Day Scholars. A day scholar is defined as a student at college who stays with his or her parents and has not opted for hostel or personal stay facilities.

- Hostellers. Hostellers are those who live away from their homes and family, in hostels, during their education.

\section{Sample}

- Sample description. The respondents were students belonging to the emerging adults (18-25 years by Arnett, 1995) category, pursuing undergraduate courses who are day scholars or hostellers.

- Sample size. A total of 123 samples was collected for the purpose of the present study out of which there were 30 females who were day scholars, 31 females who were hostellers, 31 males who were day scholars, and 31 males who were hostellers.

- Sampling method. Purposive sampling method and Snowball technique were used for the study.

\section{Inclusion criteria}

- Students pursuing undergraduate courses.

- Students staying in PG.

- Students must have stayed away from home for a minimum of 2 years.

- Students visiting home not more than once a month.

- Students living in tier- 1 cities.

\section{Exclusion criteria}

- First-year students pursuing undergraduate courses.

- Students who stay away from home but with siblings.

- Students staying in a joint family or have single/ separated or divorced parents. 


\section{Emotional Competence Among Day Scholars and Hostellers}

- Students staying in rented apartments.

- Persons with physical or mental disabilities pursuing undergraduate courses.

\section{Instruments}

- Informed Consent

- Sociodemographic Sheet

- Emotional competence scale by R. Bharadwaj and H. Sharma

\section{Procedure}

Purposive and snowball sampling method was employed for data collection. The sample under-graduate day scholars and hostellers were enrolled for this purpose of collection of data. Data was collected using the online medium and face-to-face methods. The participants were given an informed consent form and were asked to fill the sociodemographic sheet. The data were then entered manually to excel and further exported to SPSS for data analysis.

\section{Procedure for data analysis}

The data collected were scored and analyzed using Statistical package for social scienceSPSS (Version 20.0) to explore the relationship if any.

- An Independent sample T-test was used to compare the means of the two groups.

- Two-way ANOVA was used to study the interactional effect of living status and gender on emotional competence.

The study explores emotional competence between day scholars and hostellers along with gender differences in emotional competence. Descriptive statistics- frequencies, mean, standard deviation, skewness, and kurtosis were obtained for analysis and summaries. The researcher collected data from the respondents using a structured schedule, which had three sections; Informed consent, sociodemographic data, emotional competence questionnaire by Bhardwaj and Singh.

\section{Descriptive Statistics}

Table 1 Emotional Competence Day Scholars

\begin{tabular}{lllllll}
$\begin{array}{l}\text { Dependent } \\
\text { variable }\end{array}$ & Gender & N & M & SD & Skewness & Kurtosis \\
\hline Emotional & Male & 31 & 99.65 & 13.688 & -.447 & .120 \\
competence & Female & 30 & 90.43 & 15.839 & .123 & -.396 \\
\hline
\end{tabular}

Table 1 shows descriptive statistics of gender differences in emotional competence among day scholars. For this research sample, the mean score of male day scholars is 99.65; standard deviation is 13.688; Skewness is -.447 and Kurtosis is .120. The value of emotional competence is identified between the range of -1.96 to +1.96 , hence the distribution is normal. The mean score of female day scholars is 90.43; standard deviation is 15.893; skewness is .123 and Kurtosis is -.396 . The value of emotional competence is identified within the range of -1.96 to +1.96 , hence distribution is normal. 
Figure 1 Bar graph showing gender difference in emotional competence among day scholars.

\section{Day scholars}

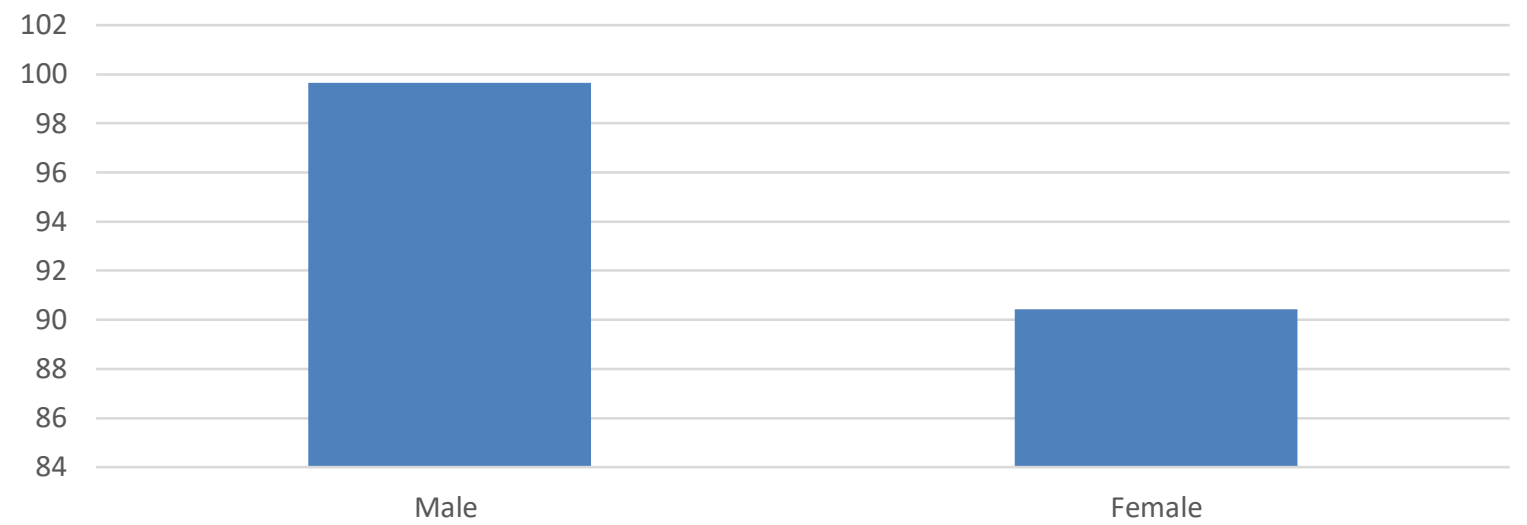

Figure 1 represents the difference in mean scores among male and female day scholars where the mean is higher for the male day scholars as compared to female day scholars.

Table 2 Emotional competence among Hostellers

\begin{tabular}{lllllll}
\hline $\begin{array}{l}\text { Dependent } \\
\text { variable }\end{array}$ & Gender & N & M & SD & Skewness & Kurtosis \\
\hline Emotional & Male & 31 & 98.39 & 14.564 & -.674 & .080 \\
competence & Female & 31 & 93.84 & 16.351 & -.237 & -.229 \\
\hline
\end{tabular}

Table 4.2 shows descriptive statistics of gender differences in emotional competence among hostellers. For this research sample, the mean score for male hostellers is 98.39; standard deviation is 14.564; Skewness is -.674 and Kurtosis is .080 . The value of emotional competence is identified between the range of -1.96 to +1.96 , hence the distribution is normal. The mean score of female day scholars is 93.84; standard deviation is 16.351 ; skewness is -.237 and Kurtosis is -.229 . The value of emotional competence is identified within the range of -1.96 to +1.96 , hence distribution is normal.

Figure 2 Bar graph showing gender difference in emotional competence among hostellers.

\section{Hostellers}

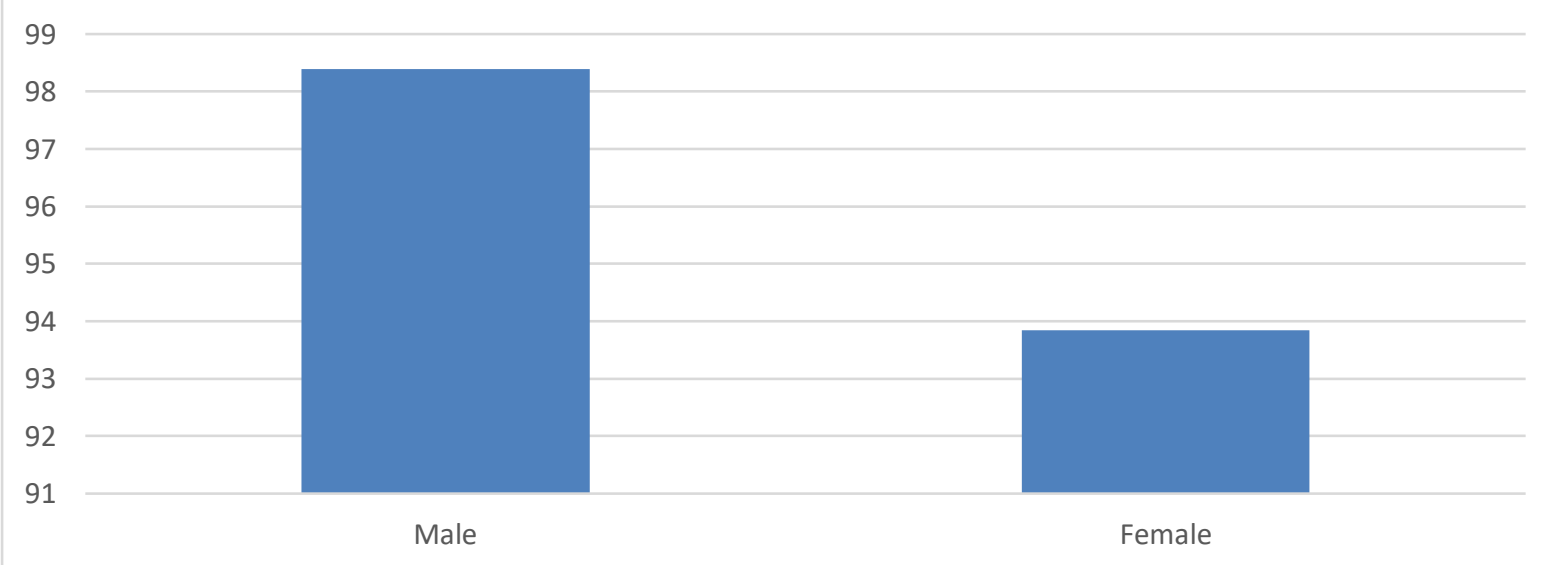




\section{Emotional Competence Among Day Scholars and Hostellers}

Figure 2 represents the difference in mean scores among male and female hostellers where the mean is higher for the male hostellers as compared to female hostellers.

\section{Inferential Statistics}

The data obtained were then scored based on the scoring guidelines and was subjected to inferential analysis to test each hypothesis. The analysis used was a t-test and two-way ANOVA for each of the hypotheses proposed.

Objective 1. To compare the emotional competence among day scholars and hostellers.

Hypothesis 1. There is no significant difference in emotional competence among day scholars and hostellers.

To identify the significant difference in emotional competence between day scholars and hostellers, an independent sample t-test was adopted. Below are the findings.

Table 3 Showing Independent t-test of emotional competence among day scholars and hostellers.

\begin{tabular}{llllllll}
$\begin{array}{l}\text { Dependent } \\
\text { variable }\end{array}$ & Groups & N & Mean & $\begin{array}{l}\text { Std. } \\
\text { Deviation }\end{array}$ & t & Df & Sig \\
\hline $\begin{array}{l}\text { Emotional } \\
\text { competence }\end{array}$ & Day scholars & 61 & 95.11 & $\begin{array}{l}15.379 \\
15.526\end{array}$ & -.358 & 121 & .721 \\
\hline
\end{tabular}

Table 4.3 represents results of independent sample t-test of emotional competence among day scholars and hostellers. For this research sample $(n=123)$, the group of day scholars $(M=95.11, S D=15.379, n=61)$ has obtained lower score on emotional competence than the group of hostellers $(M=96.11, S D=15.526, n=62) ; d f=121, t=-.358, p=.721$ which is not significant at 0.05 level Therefore, $\mathrm{p}>0.05$ hence the null hypothesis is retained.

Objective 2. To compare gender differences in emotional competence.

Hypothesis 2. There is no significant gender difference in emotional competence.

To identify the significant gender difference in emotional competence, an Independent sample t-test was adopted. Below are the findings.

Table 4 Showing Independent sample t-test of emotional competence in gender.

\begin{tabular}{llllllll}
$\begin{array}{l}\text { Dependent } \\
\text { variable }\end{array}$ & Gender & N & Mean & $\begin{array}{l}\text { Std. } \\
\text { Deviation }\end{array}$ & T & Df & $\begin{array}{l}\text { Sig. } \\
\mathbf{2}- \\
\text { tailed) }\end{array}$ \\
\hline $\begin{array}{l}\text { Emotional } \\
\text { competence }\end{array}$ & Male & 62 & 99.02 & 14.031 & 2.521 & 121 & .013 \\
\hline
\end{tabular}

Table 4.4 represents the gender difference in emotional competence. For this research sample $(n=123)$, the group of males $(M=99.02, S D=14.031, n=62)$ has obtained higher score on emotional competence than the group of females $(M=92.16, S D=16.058, n=61)$; $d f=121, t=2.521, p=.013$ which is significant at 0.05 level. Therefore, $\mathrm{p}<0.05$ hence the null hypothesis is rejected.

Objective 3. To study the effect of living status and gender on emotional competence. 


\section{Emotional Competence Among Day Scholars and Hostellers}

Hypothesis 3. There is no significant gender difference in emotional competence among day scholars and hostellers.

To identify the significant gender difference in emotional competence among day scholars and hostellers, two-way ANOVA was adopted. Below are the findings.

Table 5 Shows Levene's test

\begin{tabular}{llll} 
F & df1 & df2 & Sig. \\
.309 & 3 & 119 & .819 \\
\hline
\end{tabular}

Table 4.6 shows Levene's test to assess the homogeneity of variance. As per the table the $\mathrm{F}=.309(3,119) \mathrm{p}=.819$ which is not significant at 0.05 level. Therefore, $\mathrm{p}>0.05$ hence, the assumption of homogeneity of variance is not violated across groups.

Table 6 Results of Two-way ANOVA-Gender difference in emotional competence based on a current stay of students.

\begin{tabular}{|l|l|l|l|l|}
\hline & Df & Mean squares & F & Sig \\
\hline Gender & 1 & 1455.285 & 6.348 & .013 \\
Current stay & 1 & 35.440 & .155 & .695 \\
Gender*currentstay & 1 & 167.152 & .729 & .395 \\
\hline
\end{tabular}

Table 4.6 shows the results of two-way ANOVA conducted to examine the gender difference in emotional competence among day scholars and hostellers. The main effect of gender on emotional competence was significant at 0.05 level $[F(123,1)=6.348, p=.013]$. The main effect of current stay or current living status on emotional competence was not significant $[F(123,1)=.155, p=.695]$. There was no statistically significant interaction effect between gender and current stay of students $[F(123,1)=.729, p=.395]$. Hence Hypothesis 3 is retained.

Figure 3 shows the means of emotional competence

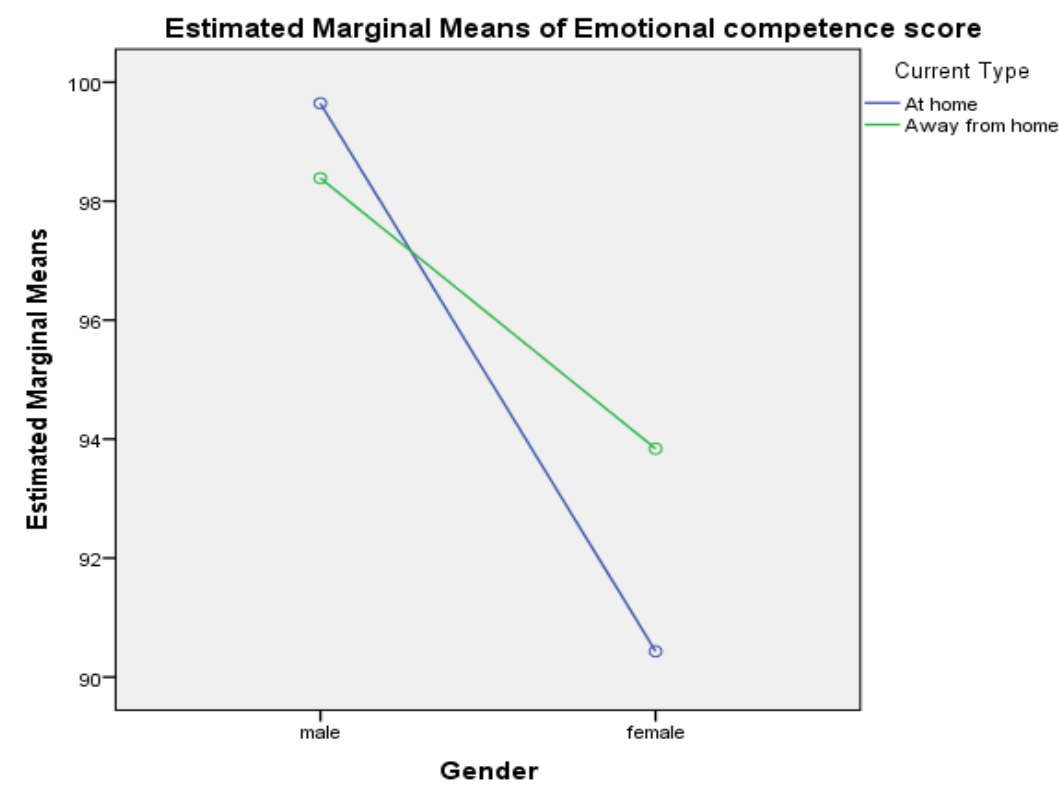

Figure 3 represents the emotional competence scores on basis of gender and living status. The graph represents that male living at home (day scholars) and away from home 
(hostellers) has a higher score on emotional competence as compared to female students staying at home (day scholars) or away from home (hosteller).

The present study aims to study the gender difference in emotional competence among day scholars and hostellers. The analysis is carried on basis of three hypotheses. A total of 123 data that matched the inclusion and exclusion criteria was considered for analysis. For this study, an Independent sample t-test and 2 X 2 Factorial design are used to test the hypotheses. The study lays emphasis on three variables, namely; gender, living status, and emotional competence. The results with respect to the objective and the corresponding hypothesis and the analysis are discussed in detail below.

Objective 1. To compare the emotional competence among day scholars and hostellers.

Hypothesis 1. There is no significant difference in emotional competence among day scholars and hostellers.

The data were analyzed using an independent sample t-test on day scholars and hostellers to assess the emotional competence among these groups. It was found that the effect of living status on emotional competence was not significant. Emotional competence is defined as the efficiency of an individual to deal with emotional situations effectively, thus this behavior is seen to be exhibited in undergraduate students and is independent of their living status. Students living with their families and students living in hostels or PG show similar levels of emotional competence. This could indicate that role of the family in the development of emotional competence is more prominent during the early years. The socialization that the students have with their peers, roommates, and significant others during college also impacts emotional competence. The result in the present study differs from the result obtained by M.S. Waddar and V. A. Aminabhavi (2010) which indicated a difference in emotional intelligence among post-graduate students staying at home and students staying at the hostel. Postgraduate students staying at home have significantly higher self-efficacy and overall emotional intelligence compared to hostilities. This signifies that emotional competence as a skill is developed through the process of socialization. Emotional competence, though interrelated is different from emotional intelligence.

Objective 2. To compare gender differences in emotional competence.

Hypothesis 2. There is no significant gender difference in emotional competence.

The data were analyzed using an independent sample t-test on sample males $(n=62)$ and females $(n=61)$ to assess the emotional competence among these groups. It was found that there was a significant gender difference in emotional competence. Male students were seen to have higher emotional competence as compared to female students. Since there is a difference in the way each gender expresses emotions and displays control over their emotions there could be a gender difference in emotional competence. The study by Sharma and Lata (2013) also indicated a similar finding that there was a significant difference in means of emotional competence among boys and girls in secondary school where boys had higher mean scores. Thus, consistency in gender difference in emotional competence as this study reveals that males are better skilled at dealing with emotional situations.

Objective 3. To study the effect of living status and gender on emotional competence.

Hypothesis 3. There is no significant gender difference in emotional competence among day scholars and hostellers.

The data were analyzed using two-way ANOVA on sample day scholars and hostellers to assess gender differences in emotional competence. The main effect of gender on emotional competence was not significant at 0.05 level. The main effect of current stay or current 


\section{Emotional Competence Among Day Scholars and Hostellers}

living status on emotional competence was not significant. There was no statistically significant interaction effect between gender and the current stay of students.

Saarni (1999) explains how individuals learn to flexibly apply a set of emotion management skills to their social environments like families, friendships, or schools. In conclusion, day scholars and hostellers both have the necessary skill for managing their emotions with respect to the demands of the social environment. For the emerging adults' category, the students are probably well equipped with the necessary set of skills, and hence living at home or away from home does not have a significant impact on the level of emotional competence. The study by Harris and Colle and Del Giudice further reflects that attachment status and early child-caregiver relationships contribute to children's understanding of emotions and affect children's emotional functioning at all levels. Therefore, the role of family members would play a significant role during the early years of students' life. Emotional competence is learned during life and develops as a process of socialization that is not restricted to family; friends, peers, and teachers also play an important in students' life in terms of emotional control and expression. Thus, a significant difference is not observed among day scholars and hostellers.

\section{CONCLUSION}

The result indicated that there is no significant difference in emotional competence among day scholars and hostellers, however, there was a significant gender difference in emotional competence. There was no significant effect of gender and living status on emotional competence.

\section{Limitation of the present study}

- A non-probability sampling technique was used for the present study and hence cannot be guaranteed that everyone falling under the population was represented in the study.

- Emerging adults living in $1^{\text {st }}$ tier cities were only considered and hence cannot be generalized to individuals across the country.

- The study focuses on students pursuing under-graduation; hence it cannot be generalized to all students.

\section{Suggestion}

There is scope for further research. Despite the limitations stated, this study is one of the first kind to study emotional competence among day scholars and hostellers. Emotional competence is not very widely studied for emerging adults' category. A wider sample can be used for further study. The study can consider the various domains of emotional competence to further study which aspect of emotional competence is significantly different for which group. The sample only included students from $1^{\text {st }}$ tier cities that are Bangalore, Mumbai, Chennai, Hyderabad, Pune, Delhi, and Kolkata. Different results may be obtained if students from rural and non-urban areas are included in the sample. Further emotional competence among day scholars and hostellers can be studied in relation to the family environment to assess the role of family members in emotional competence. The study can be inclusive of different family types as well.

\section{REFERENCES}

Arora, S., \& Kaur, S. (2017). A Comparative Study of Emotional Competence in Relation to Depression Among Adolescents of Punjab in Terms of Gender Difference. 
International Education and Research Journal, 3(3). Retrieved April 20, 2019, from http://ierj.in/journal/index.php/ierj/article/view/739.

Baruah, K., \& Saha, K. (2018). Emotional Competence of Adolescent Boys And Girls: A Comparative Study. Indian Journal of Applied Research,8(5). Retrieved January 27, 2019, from https://wwjournals.com/index.php/ijar/article/view/4189.

Basaiawmoit, B.S. (2014). Emotional Competence And Family Environment Of School Children (13-15 Years). Krishikosh Institutional Repository. Retrieved on March 28, 2019 http://krishikosh.egranth.ac.in/displaybitstream?handle $=1 / 5810029822$

Bhat, R. H., \& Khan, S. M. (2018). Emotional competence: Review. National Journal of Multidisciplinary Research and Development,3(1), 44-49. Retrieved January 26, 2019.

Goleman, D. (1998). Working with emotional intelligence. New York: Bantam Books.

Goleman, D. (1995). Emotional Intelligence: Why it can matter more than IQ. New York: Bantam Books

Juyal, S. L., \& Dandona, A. (2012). Emotional Competence Of Sports And Non-Sports Personnel: A Comparative Study. International Journal of Behavioral Sciences. 27. 41-52. Retrieved January 11, 2019, from https://www.researchgate.net/publication/317066486_EMOTIONAL_COMPETENC E_OF_SPORTS_AND_NONSPORTS_PERSONNEL_A_COMPARATIVE_STUDY

Jacob, A. M., \& Kaushik, A (2017). A Comparative Study to Assess the Health Status and Academic Progress among Day Scholars and Hostellers in a Selected College of Nursing in New Delhi. International Journal of Nursing \& Midwifery. 4(2). $\begin{array}{llll}\text { Retrieved on } & 2019\end{array}$ from https://medical.adrpublications.in/index.php/IntlJNursingandMidwiferyRes/arti cle/view/1207

Kumar, A., \& Thapar, V. (2015). Emotional Competence and Adjustment of Secondary School Students Belonging to Nuclear Families. Indian Journal of Research,4(8). Retrieved January 27, 2019, from https://www.worldwidejournals.com/paripex/recent_issues_pdf/2015/August/August _2015_1439547557_56.pdf.

Lau, P. S., \& Wu, F. K. (2012). Emotional Competence as a Positive Youth Development Construct: A Conceptual Review. Retrieved January 24, 2019, from https://www.hindawi.com/journals/tswj/2012/975189/

Saarni, C. (2011). Emotional Development in Childhood. Encyclopedia on Early Childhood Development. Retrieved on December 2, 2018, from http://www.childencyclopedia.com/emotions/according-experts/emotional-development-childhood.

Saarni, C. (1999). A Skill-Based Model of Emotional Competence: A Developmental Perspective. Retrieved from https://files.eric.ed.gov/fulltext/ED430678.pdf

Sandhya, G. (2017). Emotional Competencies Of Adolescents Of Working And Nonworking Mothers.

Scholarly Research Journal. 4(29), 4651-4660. Retrieved on April 10, 2019 http://www.srjis.com/pages/pdfFiles/149311186037.\%20Paper_Dr.\%20Sandhya\%20 Final.pdf

Sharma, H. C., \& Bharadwaj. (2016). Manual for the Scale of Emotional Competence. India: Pankaj Mapan. Sharam \& Bhardwaj. (2007). Emotional Competence Scale (ECS). Agra: National Psychological Corporation

Sharma, S., \& Lata, S. (2013). Comparative Study Of Emotional Competence Among Students In Relation To Their Gender And Type Of Institute. International Journal of Behavioural and Movement Science, 2(2). Retrieved January 1, 2019. 


\section{Emotional Competence Among Day Scholars and Hostellers}

Shazia., \& Kiran, U. V. (2018). Psychological well-being and emotional competence among children living in shelter home and street. International Journal of Applied Social Science, 5(12), 2171-2173. Retrieved April 22, 2019, from file:///C:/Users/Prerana/Downloads/Social-Science-5_A-2171-2173-Full-Paper.pdf.

Singh, M. (2014). Degree of Social Competence Among The School Students. Scholarly Research Journal for Humanity Science and English Language. 3(14). Retrieved on March 27, 2019 http://www.srjis.com/pages/pdfFiles/14685781185.\%20Dr\%20Mangal\%20Singh.pdf

Sunny, J., Ahammed, A., Gopi, A., Tom, A., \& Kurian, M. A. (2018). Gender Difference in Emotional Intelligence among Adolescent Hostellers and Day Scholars. International Journal of Current Research and Academic Review, (5), 61-69. Retrieved January 31, 2019, from http://www.ijcrar.com/special/5/Jesty Sunny, et al.pdf

Vaida, S. 2014. (2014). Emotional Intelligence versus Emotional Competence. Journal of Psychological and Educational Research, (22), 26-33. Retrieved from https://www.researchgate.net/publication/263274155_Emotional_Intelligence_versus Emotional_Competence

Waddar, M. S., \& Aminabhavi, V. A. (2010). Self-Efficacy and Emotional Intelligence of PG Students. Journal of the Indian Academy of Applied Psychology,36(2), 339-345. Retrieved December 30, 2, from http://medind.nic.in/jak/t10/i2/jakt10i2p339.pdf

William, M. S. W., \& Jansi, V. (2017). A Study on Emotional Competence among College Students. Research on Humanities and Social Sciences. 7(17). Retrieved on May 2, 2019 https://www.iiste.org/Journals/index.php/RHSS/article/view/38511/39595

\section{Acknowledgement}

I would like to extend my sincere acknowledgment to the Indian Institute of Psychology and Research (IIPR), Bangalore University, for providing me with a platform to carry out this research study. I would further extend my sincere gratitude to Dr. Elizabeth Jasmine, Principal, IIPR, Bangalore, for her valuable feedback and suggestions. I would like to thank Dr. Sunitha Damodar, Coordinator Academics and Associate Professor, IIPR, Bangalore, my guide and research supervisor, for her unwavering support and encouragement throughout the research. I am indebted to my co-guide Mr. Nachiketh B. for his encouragement and insightful comments. Without their expertise and inputs, this research would not have reached its completion. Last but not the least, I would like to thank my family and fellow classmates for their continued support and encouragement throughout my master's degree.

\section{Conflict of Interest}

The author(s) declared no conflict of interest.

How to cite this article: Sinha P., Damodar S. \& Nachiketh B. (2021). Emotional Competence Among Day Scholars and Hostellers. International Journal of Indian Psychology, 9(4), 2096-2108. DIP:18.01.198.20210904, DOI:10.25215/0904.198 